\title{
Manufacture of Continuous Glass Fiber/Polylactic Acid (PLA) Composite and Its Properties
}

\author{
Jeong U Roh ${ }^{\mathrm{a}}$, Woo Il Lee ${ }^{\mathrm{b}, *}$ \\ aDepartment School of Mechanical and Aerospace Engineering, Seoul National University. \\ ${ }^{b}$ Department School of Mechanical and Aerospace Engineering, Seoul National University. Email: wilee@snu.ac.kr
}

\begin{abstract}
The continuous glass fiber reinforced polylactic acid (PLA) prepreg was manufactured by direct melt impregnation. The mechanical and thermal properties of PLA prepreg were observed. The properties of PLA prepreg were compared with the neat PLA and the injection molded glass fiber/PLA composite. The PLA prepreg having a fiber volume fraction of $27.7 \%$ shows well enhanced tensile strength of $331.1 \mathrm{MPa}$, flexural strength of 528.6 MPa, and flexural modulus of $24.0 \mathrm{GPa}$. The enhancement in the heat deflection temperature (HDT) and the crystallinity were also observed. The fracture interface was inspected by FE-SEM. The degree of impregnation as a function of pulling speed was measured. The degree of impregnation at the pulling speed of $5 \mathrm{~m} / \mathrm{min}$ reached over $90 \%$ in this research.
\end{abstract}

Keywords: Continuous glass fiber; prepreg; fiber reinforced thermoplastic; heat deflection temperature (HDT); mechanical properties; polylactic acid (PLA)

\section{Introduction}

Polylactic acid (PLA) is one of bio-degradable polymers being used widely from as packaging material to medical applications $[1,2]$. In these days, applications to automobiles have attracted industrial attention. However, eco-friendly materials, in many cases, have weak thermal stability to be used for vehicles. PLA, on the other hand, has better performance than other bio-degradable polymers. Nevertheless, it has disadvantages of low crystallinity and low heat deflection temperature (HDT). For example, the HDT of PLA (NatureWorks LLC, 4032D) is $50.4{ }^{\circ} \mathrm{C}$ while the HDT of polypropylene (PP) is $108{ }^{\circ} \mathrm{C}[3,4]$. PP is one of the most widely used polymers for automotive applications and the HDT of PLA is much lower than the value required for automotive industry. In order to increase the HDT of a polymer, there are several ways such as increasing the glass transition temperature, Tg, applying reinforcement, and increasing the crystallinity. Generally, higher aspect ratio of reinforcement in the matrix gives better reinforcing effect. Furthermore, it is well known that the crystallinity can be increased at high shear rates [5]. Therefore, in this study, continuous glass fiber was chosen for the reinforcement and the melted PLA resin was impregnated into the continuous fiber tow by using the direct melt impregnation method to induce high shear rates. The direct melt impregnation method is common technique and there are several variations in the process by combining elements such as fixed pin, porous impregnation wheel and freely rotating pin [6]. In this study, the melt pool with fixed pins was applied to impregnate PLA resin into the continuous fiber tow.

Higher shear rate can be applied to the PLA resin by forcing the resin to flow between the continuous fibers. This can be achieved by inducing resin pressure through pulling the fiber tow over the impregnation pin. For the PLA prepreg thus manufactured, degree of impregnation as a function of pulling speed was observed as well as mechanical properties, crystallinity, HDT, and the fracture surface.

\section{Experiment}

\subsection{Materials}

PLA resin (NatureWorks LLC, 4032D) was used for the matrix of prepreg. The glass fiber (Owens Corning, 2400 tex) was used for the reinforcement. The fiber diameter was $22.4 \mu \mathrm{m}$ and the width of the fiber bundle was $6 \mathrm{~mm}$. The roving was treated with the same sizing for PP matrix.

\footnotetext{
${ }^{*}$ Corresponding author. Tel.: +82-2-880-7008

School of Mechanical and Aerospace Engineering,

Seoul National University, Seoul 151-742, Korea

This manuscript has been reproduced from a paper published in Korean in Composites Research, The Journal of the Korean Society for Composite Materials, 26(4): 230-234, 2013.
} 


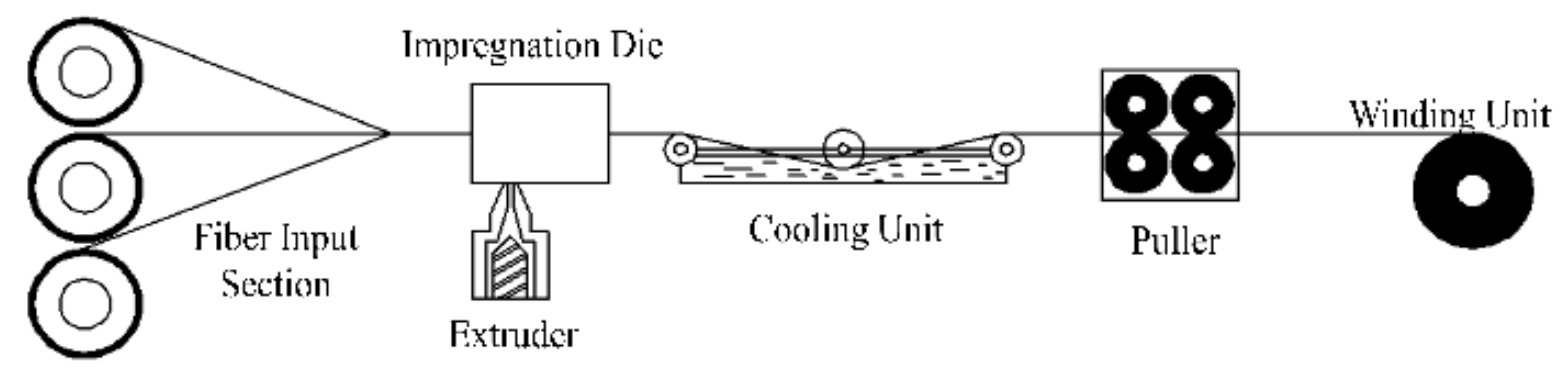

Figure 1. Illustration of the setup for manufacturing PLA prepreg.

Table 1. Thermal properties of neat PLA and PLA prepreg

\begin{tabular}{|c|c|c|c|c|c|}
\hline & $T_{g}\left({ }^{\circ} \mathrm{C}\right)$ & $T_{c}\left({ }^{\circ} \mathrm{C}\right)$ & $T_{m}\left({ }^{\circ} \mathrm{C}\right)$ & $\Delta \mathrm{H}_{\mathrm{m}}(\mathrm{J} / \mathrm{g})$ & $\mathrm{X}_{\mathrm{c}}(\%)$ \\
\hline Neat PLA & 59.03 & 105 & 166 & 17.1 & 18.2 \\
\hline PLA prepreg & 58.2 & 110.9 & 165.2 & 16.85 & 32.4 \\
\hline
\end{tabular}

\subsection{Setup for manufacturing of PLA prepreg}

The setup consisted of 5 components: unwinding unit, pin impregnation die, cooling unit, puller and winding unit. Fiber bundle was unwound with a constant tension by using the unwinding unit. The constant tension is important to control the input position of fiber bundle [7, 8]. The guided fiber bundle was impregnated by using the direct impregnation method. The pin impregnation die consisted of three $10 \mathrm{~mm}$ diameter cylindrical pins and two $8 \mathrm{~mm}$ diameter cylindrical pins. At the bottom and upper plate of the pin impregnation die, the heaters were introduced to maintain the preset temperature for the resin at $220^{\circ} \mathrm{C}$. The consumed resin was replenished by the extruder continuously. A single screw extruder (Uenoyama Kiko) was used to deliver the molten resin into the pin impregnation die. The impregnated fiber bundle after the pin impregnation die was cooled by using a water cooling vat. The caterpillar type puller was applied to pull the fiber bundle. The pulling speed was controlled from $0.5 \mathrm{~m} / \mathrm{min}$ to $5 \mathrm{~m} / \mathrm{min}$. After the puller, the prepreg was wound with a constant torque by the winding unit. The illustration of the setup for manufacturing of the PLA prepreg is shown in Fig. 1.

\subsection{Characterization}

The tensile strength, the flexural modulus and strength, and the inter-laminar shear strength of the manufactured specimens were measured using a universal testing machine (UTM) (Lloyd Instruments, LR 50K). In order to obtain a data point, at least five tests were done and the results were averaged.

The tensile strength was measured following ASTM D 3039/D 3039M standard with the crosshead speed of 2 $\mathrm{mm} / \mathrm{min}$. The flexural strength and modulus were measured according to ASTM D 790 with the crosshead speed of $5 \mathrm{~mm} / \mathrm{min}$. Testing of the inter-laminar shear strength of the specimens was done following the ASTM D 5379/D 5379M with the crosshead speed of $2 \mathrm{~mm} / \mathrm{min}$.

The fiber volume fraction of PLA prepreg was observed by a close inspection of polished cross-sections of impregnated samples with five test values per one condition. A microscope (Leica, Type 020-520.008 $\mathrm{DM} / \mathrm{LM}$ ) with a mounted CCD camera (Nikon, Coolpix 950) was used to observe the polished cross-section of the prepreg. The test specimens were mounted with epoxy resin and the cross-sections were polished using a series of sand papers with increasing finish $(400,800,1200,2400$ and 4000 grains/in).

The crystallization behavior was observed by differential scanning calorimetry (DSC) (Perkin Elmer, DSC7) in $\mathrm{N} 2$ atmosphere. In the DSC analysis, the samples were first heated to $200{ }^{\circ} \mathrm{C}$ with the temperature increasing at a rate of $10{ }^{\circ} \mathrm{C} / \mathrm{min}$. After complete melting, the samples were cooled down to $30{ }^{\circ} \mathrm{C}$ at a rate of 10 ${ }^{\circ} \mathrm{C} / \mathrm{min}$. They were then heated again to $200{ }^{\circ} \mathrm{C}$ at a rate of $10{ }^{\circ} \mathrm{C}$ per a minute. In this way, the crystallization as well as the melting curves of the composite was obtained. The crystallinity of PLA prepreg could be evaluated using the following equation:

$$
X_{c}=\frac{\Delta H_{m}}{W_{p} \Delta H_{m}^{0}}
$$

where $W \mathrm{p}$ is the weight fraction of the polymer, $\Delta H \mathrm{~m}$ the measured melting enthalpy, and $\Delta \mathrm{H} 0 \mathrm{~m}$ the melting enthalpy of the $100 \%$ crystalline PLA. $\Delta \mathrm{H} 0 \mathrm{mis}$ taken as $93.7 \mathrm{~kJ} / \mathrm{kg}$ from the literature [9].

The heat deflection temperature (HDT) was measured following ASTM D648 using the heat distortion tester (Toyoseiki, M-2). For the test, a constant load of $0.46 \mathrm{MPa}$ was applied at the center of the three-point bending flexural coupon bar sample. The sample was heated from the room temperature to $200{ }^{\circ} \mathrm{C}$ at a rate of $2{ }^{\circ} \mathrm{C} / \mathrm{min}$.

The specimens used for the tests were made from the prepreg prepared using the manufacturing setup mentioned

above. For producing the prepreg continuously, the pulling speed of $1 \mathrm{~m} / \mathrm{min}$ and the setting temperature of $220{ }^{\circ} \mathrm{C}$ were applied. 


\section{Results and Discussion}

\subsection{Degree of impregnation}

The degree of impregnation as a function of pulling speed was observed by using the microphotographs of the cross-sections of samples. It was defined as the ratio between the number of impregnated fibers and the total number of fibers in a tow. The results are shown in Fig.2. From the $1 \mathrm{~m} / \mathrm{min}$ to the $5 \mathrm{~m} / \mathrm{min}$ of pulling speed, the degree of impregnation was over $90 \%$. Especially, the degree of impregnation at the pulling speed of $5 \mathrm{~m} / \mathrm{min}$ reached $92.5 \%$.

\subsection{Mechanical properties}

The incorporation of continuous glass fibers into PLA matrix produces an enhanced tensile and flexural strengths and a higher flexural modulus in the fiber axis direction. The average tensile strength of PLA prepreg was 331.1 $\mathrm{MPa}$, the average flexural strength of PLA prepreg was $528.6 \mathrm{MPa}$, and the average flexural modulus of PLA prepreg was 24.0 GPa. Compared with the neat PLA and the injection molded glass fiber/PLA composite having a fiber volume fraction (Vf) of $17.0 \%$, the PLA prepreg having a fiber volume fraction (Vf) of $27.7 \%$ shows much higher strength than the neat PLA (tensile strength: 62.9 $\mathrm{MPa}$, flexural strength: $98.8 \mathrm{MPa}$ ) and the injection molded glass fiber / PLA composite (tensile strength: 80.2 $\mathrm{MPa}$, flexural strength: 108.9 MPa) [10].

The flexural modulus was about 7.3 times larger than that of the neat PLA (flexural modulus: $3.3 \mathrm{GPa}$ ), about 2.9 times larger than the injection molded glass fiber/PLA composite (flexural modulus: 8.2 GPa). The average interlaminar shear strength of PLA prepreg composite in the perpendicular direction of fiber axis was 33.2 MPa. The results are shown in Fig. 3.

\subsection{Crystallization}

The glass transition temperature ( $\mathrm{Tg}$ ), the crystallization temperature (Tc), and the melting temperature $(\mathrm{Tm})$ of the PLA prepreg composite were observed by the DSC. The results are shown in Table 1.

As can be seen, Tg and Tm of the PLA prepreg were not changed notably from the neat PLA, while Tc and the crystallinity were increased. Crystallinity of the PLA prepreg was increased to $32.4 \%$ from $18.25 \%$ of the neat PLA. The increase in the crystallinity is likely due to the high shear rate applied during impregnation. The application of shear is known to increase the orientation of the molecular chain in the polymer melt and the nucleation rate [5] and thus to facilitate crystallization. Ultimately, the increase in the crystallinity of PLA prepreg is believed to affect the increase of mechanical properties.

Table 2. HDT of neat PLA and PLA prepreg

\begin{tabular}{cc}
\hline & HDT $\left({ }^{\circ} \mathrm{C}\right)$ \\
\hline Neat PLA [3] & 50.4 \\
\hline PLA prepreg & 100 \\
\hline
\end{tabular}

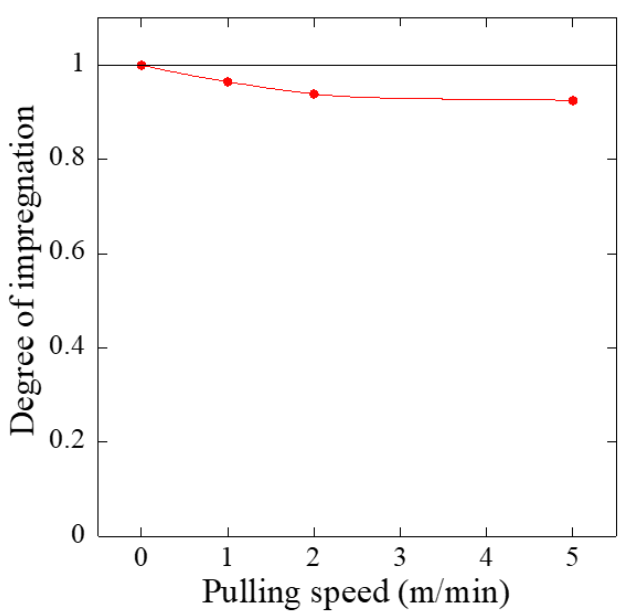

Figure 2. Degree of impregnation as a function of pulling speed

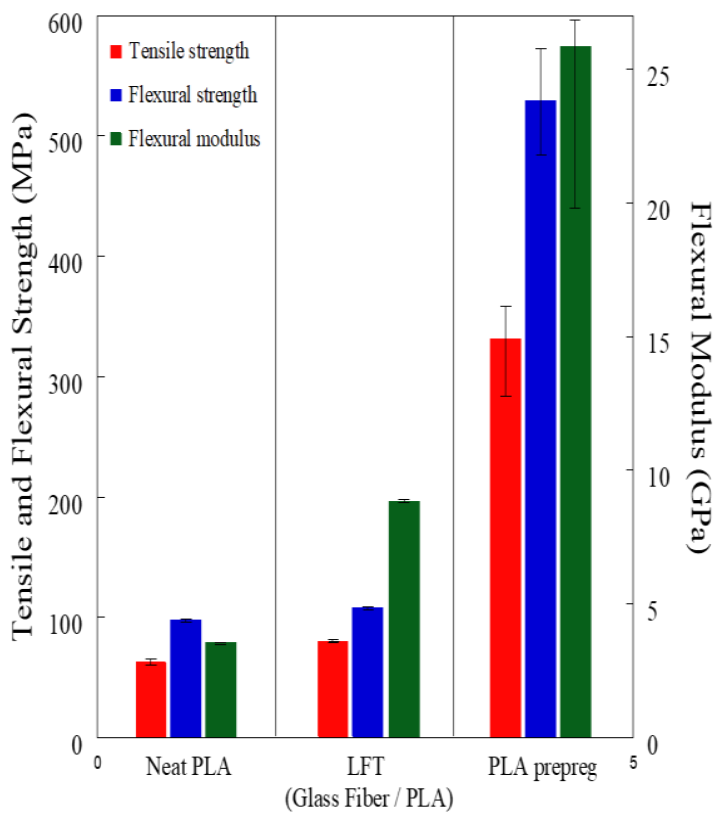

Figure 3. Mechanical properties of the composite specimen made with PLA prepreg

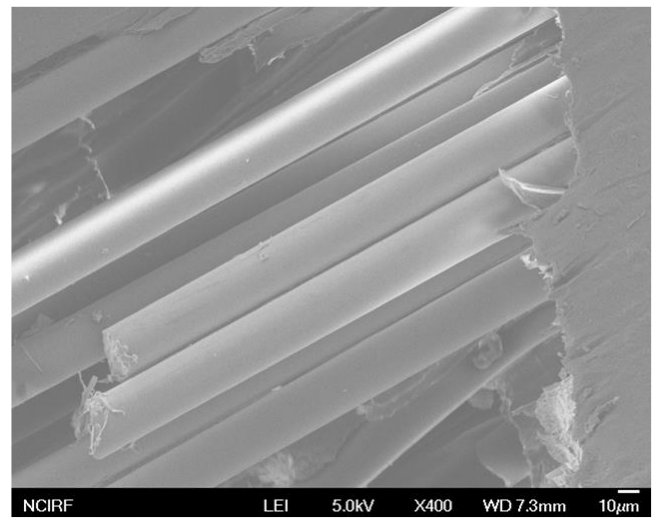

Figure 4. Fracture interface of tensile test specimen made with PLA prepreg 


\subsection{Heat deflection temperature (HDT)}

The HDT of PLA prepreg composite was enhanced as shown in Table 2. The HDT of PLA prepreg composite was $100{ }^{\circ} \mathrm{C}$ while the HDT of neat PLA was $50.4{ }^{\circ} \mathrm{C}$. There are several reasons for the increase in the HDT of polymer; increase of $\mathrm{Tg}$, presence of the reinforcement, and increase in the crystallinity. Above all, the introduction of high aspect ratio reinforcement and the increase in crystallinity were considered as main reasons for the increase in HDT in this study.

\subsection{The fracture interface}

The fracture interface of tensile test specimen of PLA prepreg composite was observed with FE-SEM (JSM6700F, JEOL) as shown in Fig.4. As can be seen, surface of glass fibers was clean and the PLA was not elongated well. It shows that the adhesion between the PLA and glass fiber is weak.

\section{Conclusions}

The manufacture and evaluation of PLA prepreg were considered. At the pulling speed of $5 \mathrm{~m} / \mathrm{min}$, the degree of impregnation was over $90 \%$. For the PLA prepreg, the mechanical properties were considerably increased. Besides the high aspect ratio of reinforcement, the high shear rate during the processing and the resulting crystallinity were thought to be responsible for the increase in mechanical properties and thermal stability. For the manufacturing of PLA prepreg, the direct melt impregnation method seemed to be working and served the purpose. The necessity of modification of the interface between the fiber and the matrix was evident.

\section{Acknowledgement}

This work was supported by the WCU(World Class University) program through the National Research Foundation funded by the Ministry of Education, Science and Technology (R31-2008-000-10083-0).

\section{References}

[1] Drumright R.E., Gruber P.R., Henton D.E.. (2000). Polylactic Acid Technology, Adv. Mater., 12(23); pp.1841-1846.

[2] Athanasiou K.A., Niederauer G.G., Mauliagrawal C. (1996). Sterilization, toxicity, biocompatibility and clinical applications of polylactic acid/polyglycolic acid copolymers, Biomoterids, 17; pp. 93-102.

[3] Shi Q.F., Mou H.Y., Li Q.Y., Wang J. K., and Guo W.H.. (2012). Influence of heat treatment on the heat distortion temperature of poly(lactic acid)/bamboo fiber/talc hybrid biocomposites, Journal of Applied Polymer Science, 123; pp.2828-2836.

[4] Jarus D., Scheibelhoffer A., Hiltner A. and Baer E. (1996). The Effect of "skin-core" morphology on the heat-deflection temperature of polypropylene, Journal of Applied Polymer Science, 60; pp.209219.

[5] Fritzsche A.K. and Price F.P. (1974). Crystallization of polyethylene oxide under shear, Polymer Engineering and Science, 14(6); pp. 401 412.

[6] Proefschrift. (2008). PhD thesis, Delft University of Technology, The Netherlands

[7] Gaymans R.J. and Wevers E. (1998). Impregnation of a glass fibre roving with a polypropylene melt in a pin assisted process, Composites Part A, 29A; pp.663-670.

[8] Bijsterbosch, H., Gaymans R.J. (1993). Impregnation of glass rovings with a polyamide melt. Part 1: Impregnation bath, Composites Manufacturing, 4(2); pp.85-92.

[9] Nam J.Y., Ray, S.S., Okamoto M., (2003). Crystallization Behavior and Morphology of Biodegradable Polylactide/Layered Silicate Nanocomposite, Macromolecules, 36; pp.7126-7131.

[10]Huda M.S., Drzal L.T., Mohanty A.K., Misra, M. (2006). Chopped glass and recycled newspaper as reinforcement fibers in injection moulded poly(lactic acid) (PLA) composite: A comparative study, Composites Science and Technology, 66; pp.1813-1824. 